\title{
The Qualitative Comparative Analysis of Chinese NIMBY
}

\author{
Based on the Perspective of Mediated Contention
}

\author{
Lu Wang \\ School of Political Science and Public Administration \\ University of Electronic Science and Technology of China \\ Chengdu, China 611731
}

\begin{abstract}
With the advance of urbanization, the resistance movements caused by NIMBY facilities are appearing endlessly. This thesis, combining Theory social movement with Mediated contention and based on NIMBY movement, makes a comprehensive analysis of several cases through Qualitative Comparative Analysis and presents the evolution process of NIMBY movement. The study shows the reason why NIMBY movement evolves into violent group events is the combination of some essential elements, including the form of struggle, participants' protesting activities and their active use of media. The division of administrative system has little influence on its evolution, while the framing process and Elite alliance split have a say in explaining this, but they are not necessary conditions. New media and traditional media are employed together in NIMBY movement, and there is no obvious distinction for their status. Based on this, the author hold the view that the legal rights of the public should be taken seriously and public participation in deciding where to locate NIMBY facilities should be strengthened; what's more, it is advisable to establish effective explanation mechanism and enhance public confidence. Besides, the government should spare no efforts to realize the Mediatization of running a state and grasp the dominance of communication.
\end{abstract}

Keywords-NIMBY; mediated contention; social movement; qualitative comparative analysis

\section{INTRODUCTION}

With the constantly advance of urbanization, a large number of NIMBY facilities are established such as waste treatment plants, crematories and hospitals to meet the increasingly living needs, which, as a result, confront Chinese cities with more and more NIMBY problems. If dealt with improperly, such problems are likely to result in resistance movements and cause great pressure on social stability. In the meantime, the development of new media technology is bringing about a new round of communication revolution which is expected form a new "mediated society"[1], through various media forms, abundant media contents together with complex media influence. As a public sphere, modern mass media is important not because it develops an equal, open and free public communication space, but because it provides a kind of publicity-"visible transparency". That is, when the rage of the public points to the government, "under the watchful eyes of the public" will bring new risk to government management, and this can be a new weapon in the hands of resisters. With the constantly advance of urbanization, a large number of NIMBY facilities are established such as waste treatment plants, crematories and hospitals to meet the increasingly living needs, which, as a result, confront Chinese cities with more and more NIMBY problems. If dealt with improperly, such problems are likely to result in resistance movements and cause great pressure on social stability. In the meantime, the development of new media technology is bringing about a new round of communication revolution which is expected form a new "mediated society"[1], through various media forms, abundant media contents together with complex media influence. As a public sphere, modern mass media is important not because it develops an equal, open and free public communication space, but because it provides a kind of publicity-"visible transparency". That is, when the rage of the public points to the government, "under the watchful eyes of the public" will bring new risk to government management, and this can be a new weapon in the hands of resisters.

Nowadays, more and more events of resistance for safeguarding rights and interests occur, and over the course of combination of NIMBY movement and new media, what is the characteristics and implications of such "mediated" resistance? What is the influence of the new media on resistance and on the society? These questions are worth deeply and systematically studying. This thesis, combining theory of social movement with mediated contention and based on NIMBY movement, makes a comprehensive analysis of several cases through Qualitative Comparative Analysis (QCA) and presents the mechanism of NIMBY movement evolution.

\section{RESEARCH PROCESS}

\section{A. Selection of Cases}

Based on several NIMBY movement cases, this thesis makes comparative analysis and obtains the logical relationship between the condition and the result of NIMBY movement evolution. Through full text search by inputting the keyword "NIMBY" in Chinese important paper full-text database of China National Knowledge Infrastructure (CNKI), 
522 papers are found. According to the words "NIMBY movement" referred to in these papers, relevant data were searched in CNKI database and classified. In addition, by searching in other information platforms such as Baidu and SinaWeibo, forty typical cases were finally selected based on a comprehensive consideration of many factors including the typicalness, representativeness, timeliness, etc.

TABLE I. TYPICAL CASE OF NIMBY MOVEMENT

\begin{tabular}{|l|l|l|}
\hline S/N & \multicolumn{1}{|c|}{ Typical case of NIMBY event } & Year \\
\hline 1. & Beijing Asuwei Waste Incineration Power Plant & 2010 \\
\hline 2. & Dalian PX Project & 2011 \\
\hline 3. & Guangzhou Jiangmen Heshan Nuclear Power Plant & 2013 \\
\hline 4. & Nantong Large-scale seaward sewage discharge project & 2012 \\
\hline 5. & Sichuan Pengzhou PX Project & 2014 \\
\hline$\cdots \cdots$ & $\ldots \ldots$ & $\ldots \ldots$ \\
\hline 39. & Zhejiang Haiyan Waste Incineration Plant & 2016 \\
\hline 40. & Guangzhou Jinshazhou natural gas station & 2015 \\
\hline
\end{tabular}

\section{B. Selection of Variables}

1) Social movement theory: According to the applicability of the explanation of the social movement theory to NIMBY movement, explanatory variables are selected based on "political opportunity structure", "resource mobilization theory" and "framing process".

a) Political opportunity structure: The scholar Eisinger was the first to bring political opportunity structure into the research of social movement, who held that "political opportunity structure mainly refers to the property of a regime, open or closed" [2]. Mc Adam called on to distinguish "political opportunity" from other advantageous conditions and highlight its "political" characteristics. Moreover, he defined "political opportunity structure" as four dimensions: "degree of openness of the regime", "degree of stability of elite alliance", "elite alliance or not" and "the suppression ability and tendency of a country"[3]. Tarrow divided political opportunity into four dimensions in detail: open political access, unstable political alliance, influential ally and split of the elite [4]. The author deems that as an exogenous variable, political opportunity structure can affect the occurrence, development and result, by reflecting the cost output of participants of a NIMBY movement and the resistance imposed on them. Therefore, the author selects "elite alliance split" and "administrative system division" as the explanatory variables for surveying the political opportunity.

b) Resource mobilization theory: Resource mobilization theory was first put forward by two western scholars MacCarthy and Zald that mainly focused on the function of mobilization of all kinds of resources in social movements. The scholars sorted out the resources involved in resource mobilization theory or explained the mobilization ability of a certain resource. According to Ren Mengshan, "mobilizing structure" is a mechanism that drives individuals to gather together to participate in a collective action, mainly including social organizations and concrete resistance behaviors [5]. The author considers "mobilizing structure" as the development of the resource mobilization theory, and in
NIMBY movements, it mainly shows up as resistance organization form and resistance behaviors.

c) Framing process: Framing process refers to tactical behaviors conducted by a social group to change the understanding of themselves and the world so as to legitimize their collective behaviors and to further encourage other collective behaviors. Framing refers to a mode that helps people know, understand and mark the things happening around them [6]. Framing process focuses on the communication and narration strategies in the social movements and emphasizes the belief and understanding based on shared culture [5]. In NIMBY movements, people will use mainstream ideology and core value to create some slogans, words, symbols and signs to seek collective recognition.

\section{2) Mediated contention}

a) Attitude towards using media: The involvement of media can impose public opinion pressure on the government so as to facilitate the realization of the appeal of the resisters, so which is a strategic behavior that can be utilized by the resisters. The involvement media mainly includes two modes: the participants as active user of the media or as passive user of the media. The former one mainly reflects that the participants actively seek the support and assistance form the mass media and participants with high capacity in applying media are likely to protect their rights and interests with the help of new media [1]. During the NIMBY movement, the participants need proper channel to express their interest demands, so their attitude towards the utilization of media is critically significant.

b) The first media of exposure: For a long time, traditional media plays an important role in the transmission of public opinion, but still fail to be the platform where the public can fully release their opinion. As a traditional way of the government to release information, traditional media has been the "government mouthpiece" for the public. However, due to strict reporting procedures, the traditional media is characterized by lagging in information release. With the continuous development of media technology, integration of traditional and new media has become a developing trend in media industry, and new media is replacing a part of roles of traditional media. Compared with traditional media, new media has natural advantages. For example, without the constraint of uniform standard in reporting procedures, its fragmented information treatment is more convenient and efficient, which makes it more proper to make bottom-up resistance for the public. It can be seen that traditional media and new media have different advantages in news production, so either of them can be the first media of exposure[7].

c) Evolution of NIMBY movement: By reference to Hong Guanghui's NIMBY crisis evolution diagram (2013), "NIMBY syndrome", "NIMBY contention", "NIMBY movement" and "NIMBY conflict (event)" is the progressive process of NIMBY crisis. During the process, from the individual protest to collective protest, from the government to the manufacturer of the facilities, media, etc., all kinds of 
powers gradually get fully involved, thus the "NIMBY" event finally become a mass incident [8]. If the government does not control the development direction and mode of NIMBY movement, the NIMBY movement is likely to break the law boundary and evolve into a violent mass incident, which not only can influence social order and public security but also can damage the fundamental interests of the public. This thesis divides the evolution of NIMBY movement into two directions including "violent mass incident" and "non-violent mass incident".

\section{Variable Assignment}

\section{1) Conditional variable}

- (1) Elite alliance split is a critical condition governing the evolution of NIMBY movement to violent mass incident. The split of elite alliance embodies in the support of further development of NIMBY event of the core people including intellectuals and professionals through media play-up or other ways, on the one hand; on the other hand, embodies in the support of non-government public organizations and interest groups involved in environmental affairs such as environmental NGO through different ways. If there is any of the above two phenomena in a NIMBY case, then the variable in the logic truth table is 1 , otherwise 0 .

- (2) Division of administrative system is a critical condition governing the evolution of NIMBY movement to violent mass incident. Administrative system shows horizontal division on the one hand, that is, the poor coordination among different departments. In this case, these departments are likely to pass the buck to each other when dealing with an event; on the other hand, the administrative system shows vertical division, that is, inconsistency of interests between the central government and the local government and lack of communication and coordination between the superior government and the lower levels. In this case, ignoring relevant policies, institutions and laws issued by the central government, the local government pays more attention to local GDP instead of environment protection prescribed in the national policy. Similarly, if there is any of the above phenomenon in a NIMBY case, then the variable in the logic truth table is 1 , otherwise it is 0 .

- (3) Resistance organization form is a critical condition governing the evolution of NIMBY movement to violent mass incident. According to the resource mobilization theory, "community, mass meeting, nongovernmental organization, social networking and regional internet forum, etc.'[9]-[12] are significant organization resources. From the perspective of displaying forms, mass meeting, non-governmental organization and regional internet forum are tangible and visible organizations; community and social networking are intangible and invisible organizations. If there is any of the above resistance organization forms in a NIMBY case, the variable in the logic truth table is 1 , otherwise it is 0 .

Resistance behavior is a critical condition governing the evolution of NIMBY movement to violent mass incident. Resistance behavior refers to the resistance performance known by and performed by the resisters, which mainly includes some well-known and standardized behaviors that can attract attention of others, such as pulling protest banners, distributing brochures, sit-down and petition"[13]. Resistance behavior in a NIMBY movement usually is a action strategy adopted by the resisters in the beginning of the movement. Starting from small groups, they carry out different performances to attract more attentions so as to obtain better resistance result. In the determination of a violent mass incident, there are also similar resistance behaviors, just as in a NIMBY movement. By comparison, the resistance behaviors in a NIMBY movement involve individuals and a small number of people in a small range, while a violent mass incident involve wide-range group behaviors. Such a situation further proves that resistance behavior is a factor accelerating the evolution of the NIMBY movement. In this case, if there is any form of resistance behaviors in a NIMBY movement, then the variable in the logic truth table is 1 , otherwise it is 0 .

- (5) Framing is a critical condition governing the evolution of NIMBY movement to violent mass incident. In the recognition of the framing process, if there is any behavior of displaying a slogan, word, symbol or sign in a NIMBY movement, then the variable in the logic truth table is 1 , otherwise 0 .

- (6) Participants' active using of media is a critical condition governing the evolution of NIMBY movement to violent mass incident. For the assignment of attitude towards using media, if the participants use media actively in different stages of a NIMBY movement, such a situation is marked by 1 , otherwise by 0 .

- (7) New media as the first media of exposure is a critical condition governing the evolution of NIMBY movement to violent mass incident. In the cases selected by this thesis, if the information is exposed through new media such as the internet, Weibo, forum or blog, such a situation is marked by 1 , otherwise by 0 .

In the determination of the outcome variables, when there is a crowd gathering and creating disturbance, accompanied by deliberate agitation and malignantly violent behaviors such as impacting and smashing [14], it shows that the NIMBY movement has evolved into a mass incident with high violence. When a large number of participants of a NIMBY movement carry out collective petition, sit-down, strike, assembly, demonstration, etc., it shows that the NIMBY movement has evolved into a mass incident with low violence. Here, if a NIMBY movement has evolved into a mass incident with a low or high violence, the outcome variable is assigned as 1 , otherwise as 0 . Of course, to recognize a violent mass incident, both the degree of violence and mass incident or not shall be determined. That is, a violent incident only involving individuals and a few people is considered as a non-violent 
mass incident, corresponding to the aforesaid resistance behaviors.

2) Data analysis: Based on the assignment criteria of variable, the relevant variables in the selected 40 typical cases are assigned, and the commonly used software fs/QCA2.0 software is selected. First, a single conditional variable is analyzed, and the result includes the consistency and coverage of the single conditional variable. In the application of conventional qualitative comparative analysis, the consistency index can be used to judge whether a specified condition (combination) is considered as the sufficient condition or necessary condition of the result. When the index is greater than 0.8 , it indicates that more than $80 \%$ of cases conform to the consistency condition, and $\mathrm{X}$ can be considered as the sufficient condition of $\mathrm{Y}$. If the index is greater 0.9 , we can consider that $\mathrm{X}$ is the necessary condition of $\mathrm{Y}$. When the consistency is satisfied, the researcher can see the rate of coverage and understand the explanatory power of condition $\mathrm{X}$ (combination) to result $\mathrm{Y}[15]$ in see "Table I".

TABLE II. ANALYSIS RESUlts OF Single CONDITIONAL VARIABLE

\begin{tabular}{|l|l|l|}
\hline \multicolumn{1}{|c|}{ Variable Name } & \multicolumn{1}{c|}{ Consistency } & Rate of Coverage \\
\hline Split of the elite alliance & 0.689655 & 0.740741 \\
\hline Division of administrative system & 0.769231 & 0.740741 \\
\hline Form of resistance organization & 0.675000 & 1.000000 \\
\hline Contentious behavior & 0.870968 & 1.000000 \\
\hline Framing processes & 0.702703 & 0.962963 \\
\hline Active user of the media & 0.675000 & 1.000000 \\
\hline The first new media of exposure & 0.666667 & 0.518519 \\
\hline
\end{tabular}

From "Table II", we can see that only the contentious behavior in the consistency of single conditional variable exceeds 0.8 , which only shows that the contentious behavior is the sufficient condition of the result. Therefore, it is necessary to carry out the combination analysis of conditional variables to obtain more information. In the conditional combination analysis, the author chooses the standard analysis, and the output results can be divided into three cases: composite scheme, stingy scheme and intermediate scheme. Based on the research practice, the author has presented the analysis results of the composite scheme see "Table III".
TABLE III. COMPOSITE SChEME ANALysis Results

\begin{tabular}{|c|c|c|c|}
\hline $\mathbf{S} / \mathbf{N}$ & Condition Combination & $\begin{array}{c}\text { Unique } \\
\text { Coverage }\end{array}$ & $\begin{array}{l}\text { Consistency } \\
\text { score }\end{array}$ \\
\hline 1 & $\begin{array}{l}\text { Split of the elite alliance* Form } \\
\text { of resistance organization * } \\
\text { Contentious behavior* Framing } \\
\text { processes* Active user of the } \\
\text { media }\end{array}$ & 0.333333 & 1.000000 \\
\hline 2 & $\begin{array}{l}\text { Division of administrative } \\
\text { system* Form of resistance } \\
\text { organization* Contentious } \\
\text { behavior* Framing processes* } \\
\text { Active user of the media* } \sim \text { The } \\
\text { first new media of exposure }\end{array}$ & 0.037037 & 1.000000 \\
\hline 3 & $\begin{array}{l}\text { Split of the elite alliance* } \\
\text { Division of administrative } \\
\text { system* Form of resistance } \\
\text { organization* } \\
\text { behavior* Active user of the } \\
\text { media* The first new media of } \\
\text { exposure }\end{array}$ & 0.037037 & 1.000000 \\
\hline 4 & Solution coverage & 0.777778 & \\
\hline 5 & Solution consistency & & 1.000000 \\
\hline
\end{tabular}

From "Table III", we can see that three different condition combinations are in included in the composite scheme got by the author's analysis. The score of solution consistency and solution coverage of the output results is separately 0.777778 and 1.000000 , which indicates that the output results of this research are good.

It can be seen that the form of resistance organization, contentious behavior and active user of the media are the necessary condition combinations that NIMBY movement evolves into violent mass incidents; the split of the elite alliance and framing processes appear in the two separate combinations, and the two appear in the combination 1 together, while the unique of combination 1 is higher than that of combination and combination 3 . As a result, the split of the elite alliance and framing processes have certain explanatory power for the evolution of the NIMBY movement, but are not the necessary condition; the division of administrative system oppositely exists in combination 2 and combination 2 . Therefore, the division of administrative system has little influence on the evolution of NIMBY movement; in the three combinations, the first media of exposure is that the effect of new media in the violent mass incidents' evolution into the NIMBY movement is not obvious.

\section{CONCLUSION}

\section{A. Research Conclusions}

In this research, through the qualitative comparative analysis for 40 cases, the author systematically has presented the mechanism of the evolution of China's NIMBY movement, and drawn the following conclusions:

- The research finds that the form of resistance organization, contentious behavior and active user of the media are the necessary condition combinations that NIMBY movement evolves into violent mass incidents;

- The division of administrative system has little influence on the evolution of NIMBY movement, and 
the split of the elite alliance and framing processes have certain explanatory power for the evolution of the NIMBY movement, but are not the necessary condition

- New media and traditional media play a common role in the NIMBY movement, and there is no obvious division of status.

\section{B. Research Enlightenments}

The enlightenments for our government's response to NIMBY movement from the above conclusions:

Firstly, pay attention to the legitimate rights of the public and strengthen public participation in decision making of NIMBY facilities location. Government and builders make reasonable compensation plans to meet interests and psychological needs of public, protect the rights and interests of the public and change the location decision model of one way NIMBY facilities. Avoid protest organization formed by public gathering through legitimate public participation.

Secondly, improve the effectiveness of communication, build an effective "interpretive framework" and enhance the sense of trust of public. There will be more and more problems in the renovation and construction of urban public service facilities with the deepening of urbanization and empowerment of the new media to the public. Therefore, the government needs to improve the effectiveness of communication with the public to enhance the sense of trust of public and reduce risk perception and resistance behavior of public.

Thirdly, realize the "media" of national governance, master the dominant right of spreading and make known to the public of the information timely and effectively to prevent the information runaway, gossip, rumors and rampant inflammatory speech caused by information asymmetry to cause the NIMBY events to evolve to malignant situation.

\section{REFERENCES}

[1] Zheng Wen. "Media resistance": The vicissitudes, mechanism and the multi-case study of the media events in the decade of China's demolition and demolition. (2003-2012) [D]. Doctoral Dissertation of Fudan University. 2013.

[2] Eisinger P K. The Conditions of Protest Behavior in American Cities. The American Political Science Review,1973,67(1):11-28.

[3] McAdam D, Conceptual Origins, Current Problems, et al. Comparative Perspectives on Social Movements. Cambridge:Cambridge University Press, 1996: 23-40.

[4] Zeng Fanxu, Dai Jia, Wang Yuqi. Political opportunities for media use and environmental resistance: take anti nuclear events as an example [J]. Journal of China University of Geosciences (Social Sciences Edition). Fourth issue of 2014.

[5] Ren Mengshan. Political opportunity structure, mobilization structure and framework process__ An analytical framework and case study of the contemporary Internet and social movement $[\mathrm{J}]$. Journal of China Youth College for Political Sciences. 06 issue of 2011.

[6] Zhao Dingxin. Lectures on social and political movements[M]. Beijing: Social Sciences Academic Press. 2006.3.

[7] Xie Gengyun, Wan Xuanao. The role change of different media in public events__ An empirical study based on 2007-2011 years' major public events[J]. modern media (Journal of Communication University of China). 12 issue of 2012.
[8] Hou Guanghui, Wang Yuandi. Why is it more and more popular of nimby crisis_-An integrated attribution model [J]. Journal of Public Administration. Third issue of 2014.

[9] Han Zhiming. Interest expression, resource mobilization and agenda setting _-Descriptive analysis of the phenomenon of "making big trouble" [J]. Journal of Public Administration. Second issue of 2012.

[10] Zheng Qian. Social resistance analysis of the coupling of relative deprivation and resource mobilization-A case study of social conflicts in $\mathrm{H}$ Town, Yangzhou City, Jiangsu[J]. Journal of Public Administration. First issue of 2015.

[11] Cui Jing. The nimby struggle in the process of urbanization in China: Collective action and social learning of citizens in regional governance. Comparison of economic and social systems [J]. Third issue of 2013.

[12] Shi Dajian, Li Xiangping. Resource mobilization theory and its research dimension [J]. Journal of Guangxi Normal University: Philosophy and Social Sciences Edition. Sixth issue of 2009.

[13] Tilly, Tarot. Contentious politics [M]. Translated by Li Yizhong. Nanjing: Yilin Translation Publishing House. 2010.

[14] Peng Xiaobing, Zhu Qinyi. Study on the mechanism of the transformation from nimby avoidance to environmental mass incidents_- Take the Shifang incident in Sichuan as an example [J]. The Journal of Shanghai Administration Institute. Sixth issue of 2014.

[15] Huang Ronggui, Zheng Wen, Gui Yong. Multi channel strong intervention, framework and resistance results-Qualitative comparative analysis of fuzzy sets of 40 demolition protest cases [J]. Sociological Research. 05 issue of 2015. 